\title{
WAYS OF ORGANIZING RESEARCH ACTIVITIES OF STUDENTS IN LITERARY EDUCATION
}

\section{Saodat Kambarova}

Tashkent State University of Uzbek, Language and Literature named after Alisher Navoi ,Senior Lecturer, Doctor of Philosophy in Pedagogical Sciences (PhD)

\section{ABSTRACT}

The article discusses ways to develop research skills in high school students and attract them to scientific work. Also, the organization of students' research activities on the example of the study of "Boburnoma" and the study of the author's skills of comparative study of the peculiarities of the flora of India.

\section{KEYWORDS}

Creativity, scientific knowledge, research, logic, activity, research, research, project, design, problem, comparison.

Article Received: 18 October 2020, Revised: 3 November 2020, Accepted: 24 December 2020

Forming students' research skills in the process of continuing education today; to contain in them the essential elements of creativity, ingenuity and exploratory activity; motivation to analyze the properties of the object under study; one of the important issues was to get acquainted with the latest developments in the field of science in which he was interested and to develop the skills to use them in practice. Of course, since cognition is a creative process, the concepts of creativity and thinking cannot be imagined in isolation. Creativity is also impossible without thinking. Creation is a process of thinking. Creative thinking, in addition to expressing the intellectual qualities of the individual, also means perceiving the world in a unique emotional way, as well as understanding it with its whole being. \section{Cognition is a continuous process of} understanding the environment and the formation of new knowledge, and is a philosophical concept that embodies the active relationship of man to the world and between the subject and the object. Knowledge of the environment is reflected in the following views:

a) practical knowledge that is necessary in everyday life and is formed in the process;

b) knowledge based on scientific understanding of the universe.

The problems of scientific knowledge and scientific creativity were reflected in the views of
Eastern thinkers such as Muhammad alKhwarizmi, Abu Nasr al-Farabi, Abu Ali ibn Sina, who put forward certain theories on the subject several centuries ago. In particular, the elements of scientific knowledge are reflected in the encyclopedic scholar al-Farghani's work "Madhal un-nujum" in the form of the basics of astronomy, the model of the structure of the world, the theory of motion of celestial bodies and the rules of construction and use of astronomical instruments.

According to Farobi, logic plays a key role in the sciences, because reason is the leading criterion in this. In the teachings of the All-Knowing, knowledge is acquired through speech, contemplation, imagination and feeling; the process of thinking develops with the age of the child and acquires originality; through thinking and analysis, a person finds in himself knowledge that was previously unknown; it is emphasized that the development of innate abilities does not happen by itself, but that there is a need for a teacher or a leader in this matter". Therefore, in the teachings of Farobi, knowledge is considered an important condition for the existence of a noble society.

Coverage of all areas of scientific knowledge is a leading feature of Ibn Sina's work. According to the scholar, reasoning is based on logic, and knowledge gives the expected effect when assimilated through feeling, i.e. intuition. Logic is 
a tool of thinking. Understanding existence is based on logic.

The scientific methods of cognition developed by Abu Rayhan by Beruni Ahmad Fergani and alKhwarizmi were further improved with his valuable ideas, the importance of theoretical and logical conclusions and comparisons in the knowledge of natural phenomena was revealed.

Beruni's teaching emphasizes the development of the ability to remember what has been observed, and emphasizes the need to base this on all disciplines. In the scientific views of the scientist, the ability of man to know the world through intuition, intellect and experience is especially recognized.

According to J. Tulenov, scientific knowledge is "the process of creating knowledge with an objective meaning about the universe, things, events, processes in it, which forms a whole system that is constantly evolving and takes different forms (concept, problem, evidence, assumptions, laws, theories, doctrines).

Scientific creativity is a creative activity aimed at the composition, formation, development and rational application of scientific knowledge. While everyday knowledge is manifested in people's life experiences and practical activities, scientific knowledge requires special activities, i.e., scientific research. The generality, the deep content, the scale, the availability of methods for the acquisition of knowledge are the distinguishing features of scientific knowledge from ordinary knowledge.

It is known that in psychology, the concept of activity is considered as the activity of living organisms to meet their needs. This activity is characterized by its biological nature in animals and is understood as a vital activity. In humans, it is interpreted as "consciousness-driven activity to meet the needs of knowing the world and to change the world and man himself."

Activity is "a form of active attitude of people to the external world, a way of transforming oneself in a purposeful way, one of the important features of human existence. Only on the basis of activity can the essence of man be manifested, the existence of society, any social structure can be ensured."

According to E. Ghaziev, activity is a high form of behavior that belongs only to man and acquires a new quality, originality, which arises on the basis of activity. Activity emerges as an individual manifestation of activity, which differs from behavior by its psychological symptoms.

In our view, activity is the behavior that occurs according to a person's different needs, is guided by a perceived goal, and consists of mental and physical activity. Any activity consists of internal and external parts. Subjective (external) behaviors then turn into internal (mental) behaviors based on experiences. Work, play and education are the main types of activities. Of course, any type of activity is closely related to the formation of certain skills and competencies.

Curiosity and observation are the first signs of research. Even if high school students understand the features of objects and events that take place around them, they will not be able to draw reasonable conclusions about their essence. Overcoming such contradictions will pave the way for the development of research activities. It is expedient to identify the difference between the concepts of scientific research and educational research in the organization of research activities of high school students in secondary schools. The planned volume of work, novelty and duration will clarify the difference between them. Consequently, while research seeks a solution to an objective scientific problem, academic research implies the solution of a scientific problem that is subjective, that is, that the student himself considers to be new. If the educational problem in the process is not addressed in accordance with the existing knowledge, experience and interests of students, the learning problem will inevitably remain unresolved. Even if this problem is solved in education, it allows the student to rediscover aspects that are considered new.

According to I. Rajabova, the approach to the teaching process from the point of view of scientific research is a high stage in the development of students' cognitive activity. 
Cognitive activity is inextricably linked to the ability to present the learning problem in an interesting way and the principle of collaborative learning, which in turn requires independent forms of work that require individuality, creativity, activism and initiative from the student. They are characterized by the student's self-selection, refinement, self-monitoring, evaluation, and achievement of certain results.

In the upper grades of general secondary schools, a special place is given to the orientation of students to scientific research. In this regard, the work of encyclopedic scholar Zahiriddin Muhammad Babur, in particular, the work "Boburnoma" can be an important source of interest to students in terms of coverage of various fields of science, reviving the way of life, aspirations, beliefs and deeds of our ancestors. In the 10th grade, the study of the poet's work is approached in the "Literature" curriculum as follows: "Bobur is a great prose writer. "Boburnoma" is a unique example of Uzbek classical literature, a source of history, natural sciences, geography, ethnography, literature and art history. "Boburnoma" is a memoir. Scientific, educational and artistic value of "Boburnoma". The image of Babur in fiction.

Due to the wide range of items to be studied in the program, it is advisable to choose a specific direction from them, which implies a deeper approach to the question of what, for what purpose and how. It is noteworthy that the author's careful study of the geographical location, boundaries, flora and fauna of India is an important factor in consistently articulating the purpose, direction and essence of the study in accordance with the plan, proving with new ideas, evidence and conclusions.

The design of the study is based on the collection of information, research and presentation of the results of Bobur's work as a naturalist over a period of time. The design activity consists of the following stages:
I. Methodical instructions for students
1. Preparatory stage:

1.1. The theme of the project is determined, the relevance is based, the problem to be solved is formed.

The research topic can be recommended by the teacher or chosen by the students. The assignment is placed in front of the whole class, and students are assigned to complete it as a group or individually. This includes topics of a creative nature on literary, natural, historical, aesthetic or ethical issues.

The main protagonist of "Boburnoma" is the author himself. He follows the path of narration in conveying to readers the events he has personally witnessed as a participant. In this process, in the eyes of the reader, his worldview, taste, character traits, attitudes to relatives, people around him, the animal and plant world are embodied as a whole. The study of the author's scientific approaches to certain areas is the basis for the research topic in the "Boburnoma" in the form of "Comparative views on the flora (on the example of India)." Indeed, the practical significance and results of research begin with the correct choice of topic.

The events in "Boburnoma" depict nature, wildlife, mountains and rivers in harmony with human life. On the basis of these comparisons, the importance of the blessings of nature in human life has found its scientific confirmation. The issue of educating students in the spirit of creativity, conservation of nature, a careful look at everything around us, the mysteries of plants and animals, determines the relevance of the topic.

The existence of a problem requires the search for knowledge to solve it. Therefore, the proof of Bobur's subtle and profound observation, which during his complex life full of contradictions did not ignore even a small detail, can be the basis for the formation of a research problem. In solving the problem, it is expedient to take into account the wise views of the owner of a magical heart, who has lived all his life with purity of heart and passion for creativity.

1.2. The purpose, tasks, object and subject of the project are defined. 
The study of the facts of Bobur's activity as a botanist from the work forms the purpose of the research work. In order to achieve this goal, students are given the task of in-depth study of the work "Boburnoma". These tasks are carried out in the form of identification and reaction to the plates from the "Boburnoma" revealed by the hidden industries of the plant kingdom. The object of the project is the image of the plant in the "Boburnoma", in particular, the process of studying the characteristics of plants of India. The content, form, methods and means of studying the author's observation and storytelling skills are the subject of the project.

1.3. Types, methods and tools of design activities are selected.

Research activity is based on heuristic and research methods of education and the methods of their composition. Students collect materials on the problem from textbooks and other textbooks on Bobur's work as a naturalist, work with the text with dictionaries on the study of classical works, take excerpts from "Boburnoma" to justify their views, take a critical approach to the work. Conclusions are drawn based on a comparative study.

1.4. Get acquainted with the literature on the subject of the project.

Boburnoma, scientific articles on the life and work of the artist can be a source of information on the subject. Also, published by the International Bobur Foundation, "Boburnoma. The book "Miniatures" also serves as a tool to highlight his skills as a naturalist.

2. Research process planning stage

2.1. The research is carried out in the sequence of the plan "goal $\rightarrow$ task $\rightarrow$ result".

What should be the work plan for project implementation? In this case, a certain amount of time is set according to the simplicity or complexity of the task. Tasks are distributed according to students' abilities. Tasks include:

a) to get acquainted with the text of the work "Vaqoei sanai isno and salosina and tisa'mia" "Nine hundred and thirty-second (1525) events", ie the events of Babur's march to India; b) identify from the text the different aspects of the flora of the Indian country;

c) To study and analyze Bobur's comparative views on the plant world;

g) approach the issue in a critical spirit, substantiate, systematize and summarize their views.

d) comparison of period and space image, etc.

III. Stages of project implementation

3.1. Necessary information on the topic is collected, studied, analyzed, systematized and conclusions are drawn.

It is well known that young Babur will be forced to resign from her husband by fate. During his walks, he pays special attention to the natural landscapes of cities, villages and regions, and strives to bring to life as a master painter the uniqueness of the completely different unfamiliar terrestrial flora and fauna. Uses the comparison method in the image. Although it is possible to compare comparisons with others, it is necessary to keep in mind that it is necessary to base it on science, although it can be seen as a natural need to compare the other with one's own, to clarify unknown aspects.

Stepping on the soil of India, Babur tries not to overlook any of the creations and events in the country: "Our provinces are a different world. The mountains and the rivers and the forests and the deserts, the nature and the region and the animals and the plants, the people and the language and the rain and the people are all very special."

The author, as a zoologist, provides the reader with a wealth of information about the unique fauna of the Indian land: wild animals such as elephants, rhinoceroses, wild boars, lizards, deer, deer, monkeys, nil, zebras; birds such as peacocks, parrots, shorak, locha, durroj, pulpakor, desert chicken, chalsiy, bodana, harchal, charz; soras, manic, lacquer, duck, zumaj, sor, akka; the lion refers to the morphology and lifestyle of many terrestrial and aquatic creatures such as abi, sepsor, huki abi, karyol, kakka. The fact that the mouse, named Gilahri, lives only in trees, runs surprisingly fast and agile from high to 
low on trees; Jungle - training of birds called "claw parrots" or shorak to speak; the pleasing sound of a kakka fish with two bones sticking out of its two ears, the image of frogs that can run seven to eight years old on the surface of the water, is very interesting, and arouses in the reader a tendency to special research.

The diversity of the flora of the Indian subcontinent naturally arouses the reader's interest, and the simplicity and intelligibility of the language of the work is another factor to note. The flora of the region begins with the image of the fruit known as anba, kaila, anbuli, mahva (flower chikon), kirni, joman, kamrak, qadxil, badhal, biyrt (kunor), karun, panyola, gular, omila, chirunchi, persimmon, coconut, narrow as many ornamental and fruit trees, their characteristics, as well as information on their application will be continued.

It is worth noting that the evidence of the idea is given that the fruit of the coconut can be eaten and used as a building material: "The coin of the equipment and ships in the river is made from the skin of this coconut. The canyons of the ships are also sewn with this rope ... Before the gardens, the inside of the coconut is water. They pierce this hole and drink that water. It tastes bad, as if they had soaked palm cheese" (p. 262).

The depiction of plants and fruits belonging to the subtropical group in the play warns the reader of Bobur's scientific thinking, broad observation, and extreme meticulousness. In particular, while narrating the fruit of the orange, the author dwells on which provinces of southern Afghanistan and India it is found. Provides comparative information on fruit varieties, their distribution areas and characteristics. In particular, "Noranj will be plentiful and good in Lamgonotta and Bajur and Savadta. Lagmonat orange will be smaller and navel, delicate and abundant. It has nothing to do with the orange of Khorasan navohi. Nozuklugidindurkim,

Lagmonottin Kabulgachagakim, thirteen or fourteen trees, some oranges will be ruined until they are brought, Astrobod oranges to Samarkand, two hundred and seventy-two hundred and eighty trees, eltars. The thickness of the skin and the low oblique will not cause much damage. The majesty of the orange is orange, it has a lot of water, and it is stronger than the juice of other oranges. I said, "Khoja Kalon, in Bajur we counted one thousand oranges of this genus, and seven thousand came out" (p. 263), which shows the different aspects of oranges belonging to each region. It also means the trade of that period, the ability of the local population to send a selection of fruit to remote areas. The above information about the orange fruit alone is a measure of the author's knowledge of economics, botany, and geography.

In subsequent images, the author moves on to the description of fruits such as lemon (lemon) and orange (citron), which resemble an orange tree and its fruit. He notes that lemons are abundant in the country, the size of an egg, and if the root is boiled by a poisoned person, it will repel the damage. (P. 263).

In describing the orange fruit, it is described from its name (Bajur and Savod eli bolin, in India it is called bajuri), varieties (two types: sweet and tasteless), edible, appearance, and even from the peel to the jam: "The juice is very tasty and delicious. The splendor of the orange is like a melon. The skin is rough and rough. The tip will be thin and snout. The color of orange is yellower than the color of orange. The tree will be smaller, not a trunk tree. And it will be a bush, and the leaf will be greater than an orange leaf' (p. 263).

Of course, as events unfold, the reader's interest in the properties of the next fruit increases. Even in the depiction of the Sangtora fruit, Babur does not retreat from the art of comparison. The size of the tree, the body is like an apricot tree, the leaves are orange, the color and weight are orange, the skin is smooth, the fruit is sour, but the juice is delicious and fragrant: "it is a lemon-like stomach, not as sweet as an orange" (p. 263). It is also clear from the image that the sangtora fruit is a boon that strengthens the human stomach.

In his Galda comparisons, Babur also focuses on the biological properties of oranges such as galgal limu, chanbiri, sadofal, amradpal, karna, amalbed. 
Bobur's individuality in comparison is reflected in his ability to provide interesting and important information in the form of generalizations that capture the reader's attention. For example, when comparing amalbed with orange and lemon fruits, it recognizes that the difference between them is unique in that it is not observed in any other fruit. The properties of Amalbed are not repeated in any of the above-mentioned fruits: "It is said that if a needle is inserted into it, it will melt, whether it is a crop or a crop. Let it be orange and lemon" (p. 264).

It is noteworthy that Babur's statement that he encountered amalbed later indicates the rarity and uniqueness of this fruit: "It has been observed for three years now (p. 264).

The images talked about the excessive sweetness, sourness, or bitterness of most of the fruit, which was nauseating. These aspects raise questions in the reader about the extent to which fruits affect the human body. In particular, the melting point of the needle in the amalgam fruit sharpens its perception of its suitability for consumption.

Flowers such as josun, kanir, kiyura, jasmine in the play; the lines on the characteristics of the three seasons, such as summer, ashkol, and zimiston, complete the image of the plant world.

Assessing Bobur's skill in drawing, literary scholar D. Hoshimova emphasizes the need to "study the author's comparative approaches, not to take them lightly, to weigh any idea with the scales of reason, and then draw conclusions." After all, it is important to remember that every word of our ancestors is based on a sharp look, deep thinking, jeweled expression, and most importantly, clear and researchable facts. Indeed, the images presented in the Boburnoma are valuable not only in terms of what they have seen, but also in terms of directing the average reader to identify and limit their uniqueness through a comparative study of knowledge.

3.2. The results of the research are formalized in a ready-made form - an abstract.

IV. The project is prepared for presentation and defended.

\subsection{Presentation}

\subsection{Project protection}

The poet's constant longing and longing for the sweet smell of his native land, the hot taffeta, the purity of the air, the purity of the water, the sweet songs of the birds and the sweet taste of the fruits of other countries are not to be overlooked. For this reason, in every corner of the Indian subcontinent, as in the provinces of Movarounnahr, he built beautiful meadows, beautiful gardens, pools of water and canals always reminiscent of his homeland. Muattar transformed the country into a paradise with fragrant flowers. Hence, the combination of curiosity and alertness by nature further illuminates the infinity of Bobur's intellectual potential, which burns in the work of country and creativity. This, in turn, allows solutions to be proposed for the tasks identified in the study.

\subsection{Evaluation.}

$\mathrm{V}$. Instructions for preparation of the report on design work

5.1. Justify the problem. Research activity requires not forgetting even the smallest detail of the subject, in-depth study and comparison of sources, careful approach to each sentence in the analyzed object, finding specific news from unknown aspects and detailed research.

Sun, soil, water, climate, and similar natural factors allow us to substantiate the specificity of the issue, the subject matter under analysis. At the heart of the information about the objects in the images is not only the author's personal observations, but also conversations, inquiries with different segments of the local population or different professions for some time. It should also be noted that despite his young age, Babur carefully studied the topography, climate, population, customs, flora and fauna of the Movarounnahr region, and later used comparisons during his observations in Khorasan, Afghanistan and India. The fact that today's reader can easily read the work can be attributed to the attractiveness and comprehensibility of the language of the work. This is also another aspect of creative skill. 
5.2. Statement of conclusions. It can be said that "Boburnoma" is still a memoir of scientific and educational significance. But it should also be borne in mind that changes in place names, fauna and flora over the centuries due to the influence of natural or human factors may impair the accuracy of some data. This requires an objective approach to the issue.

5.3. Achieving the project goal, interpreting the results.

5.4. Express the content of project sections.

5.5. Demonstrate problem solving and work done.

5.6. Make a list of used literature, cite applications.

This means that any project must be structured in a single order, regardless of the topic, and the result must be clearly indicated at all stages. The advantages of designing an essay preparation process can be seen in the fact that the student begins to reveal the essence of the problem in the process of studying the topic, systematizes and organizes the ideas. The student examines, compares, tries to develop the necessary criteria for the subject, event and concept within its aspect.

In conclusion, favorable conditions are created for students to integrate the learning process with research elements by organizing research activities; the correct formation of the student's internal position, motivation for learning activities, learning and learning motives is ensured. An active attitude to the understanding of the world is formed, conditions are created for the acquisition of new knowledge at the level of existing intellectual capabilities. Most importantly, the acquisition of basic skills in the process of formation and development of scientific knowledge is achieved.

\section{REFERENCES:}

[1] Abu Nasr Farobi. A city of noble people. Responsible editor M.Khayrullaev. Tashkent: Abdulla Qodiri National Heritage Publishing House, 1993.- 224 p.

[2] Abu Rayhan Beruni - a great encyclopedic scholar. Beruni and social sciences. Tashkent: Fan, 1973. - 146 p.

[3] Davletshin M.G., Toychieva S.M. General psychology. - T.: TSPU named after Nizami, 2012. - 289 p.

[4] Zahiriddin Muhammad Bobur. Boburnoma. - Tashkent: Yulduzcha, 1989. - 368 p.

[5] Rajabova I. Approach to the education system from the point of view of systemic thinking and research // Vocational education. -Tashkent, 2013. № 1. - 28-p.

[6] Rahimov S. Abu Ali ibn Sina on education. - Tashkent: Teacher. 1967. - 167 p.

[7] Tulenov J., Valieva S. Methodology of scientific creativity. - T.: 2010. - 85 p.

[8] On approval of the state educational standard of general secondary and secondary special, vocational education. Resolution of the Cabinet of Ministers of the Republic of Uzbekistan // Collection of Legislation of the Republic of Uzbekistan. - T.: 2017 No. 14 (774), Article 230.

[9] Annotated dictionary of the Uzbek language. 5 volumes. Volume 2 - T.: "National Encyclopedia of Uzbekistan" State Scientific Publishing House, 2007. - 622 p.

[10] Goziyev E. Psychology. - T.: Teacher, 2008. $-352 \mathrm{p}$.

[11] Hoshimova D. Bobur's Comparative Views on the Flora // Language and Literature Education. - T., 2010. -№ 6. - 32-p.

[12] Rakhmonova Sh.M. The tradition of Zakhiriddin Babur in the second half of the twentieth century in Uzbek poetry // Research \& Development (IJRD). Volume: 5; Issue: 3; March 2020. - P. 199-202.

[13] Kambarova S.I. Harmony in imagery of literature and reality of life EPRA JOURNALS. International Journal of Research and Development (IJRD) Volume: 
5 | Issue: 3 | March 2020 - Peer Reviewed Journal. - B. 447-451

[14] www.ziyouz.com Library. The letter F. National Encyclopedia of Uzbekistan. Tashkent: "National Encyclopedia of Uzbekistan" State Scientific Publishing House, 2003. - 325 p. 